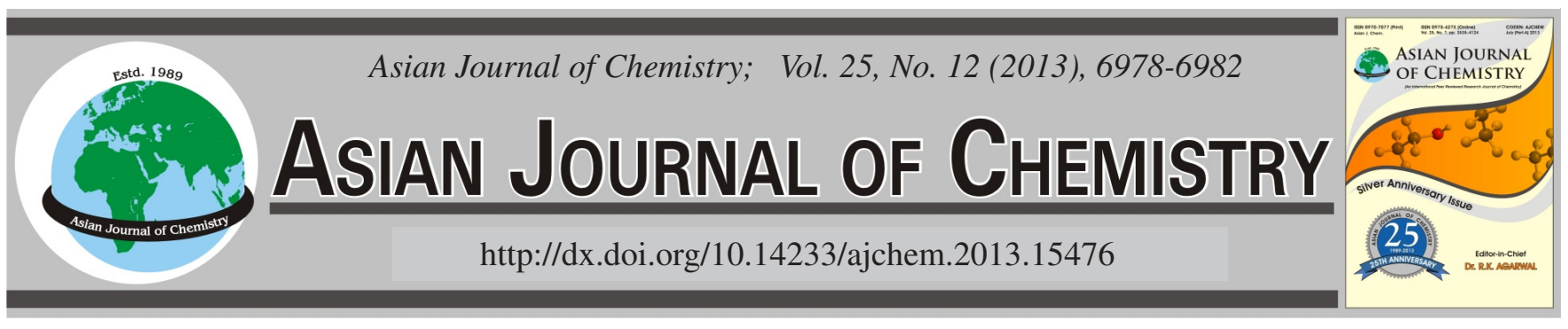

\title{
Removal of Bacterial Endotoxin Micelle from Salvia Injection by Composite Materials Ultrafiltration Membrane
}

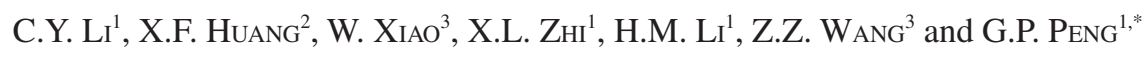

\begin{abstract}
${ }^{1}$ Department of Pharmaceutical Engineering, Pharmacy College, Nanjing University of Chinese Medicine, Nanjing City, P.R. China ${ }^{2}$ School of Pharmaceutical Engineering \& Life Science, Changzhou University, Changzhou, P.R. China

${ }^{3}$ State Key Laboratory of New-tech for Chinese Medicine Pharmaceutical Process, Jiangsu Kanion Pharmaceutical Co., Ltd., Lianyungang City, P.R. China
\end{abstract}

*Corresponding author: Tel/Fax: +86 25 86798186, E-mail: guopingpeng@ @ohu.com; licunyuok@ 163.com

\begin{abstract}
Bacterial endotoxins (BEs) produce a fever-like effect on humans upon entry into the blood system even at extremely low concentration. Bacterial endotoxins possess surface activity and their monomers can be found in aggregate micelle forms. These aggregate micelles could be dispersed onto the surface of polyethersulfone ultrafiltration membranes during removal of bacterial endotoxins from injections, and the loss of several drug active ingredients, such as salvianolic acid B, is significant. The proper balance between bacterial endotoxin rejection and active ingredient retention has not been fully elucidated. The results of this study show that the composite polymer decreased the interaction between the micelles and the membrane, resulting in the prevention and rejection of aggregated bacterial endotoxin and the loss of salvianolic acid B by less than $5 \%$. Determination of the interface interaction between the bacterial endotoxin micelles and the membrane materials will significantly improve the removal of bacterial endotoxin from injections with suitable membrane molecular weight cut off.
\end{abstract}

Key Words: Bacterial endotoxin, Aggregate micelle, Salvia injection, Composite materials, Ultrafiltration.

\section{INTRODUCTION}

Pyrogens are fever-inducing substances usually derived from microorganisms. Pyrogenic contaminations of several classes of injectable drugs represent an undeniable major health risk. Active carbon absorption is a traditional process for removal of pyrogen ${ }^{1}$ during intravenous injection preparations. However, its application is limited by saturating adsorption, complex process, and component loss. These disadvantages can be overcome by ultrafiltration. Ultrafiltration has been widely used in several injections, such as the Millipore ultrafiltration membrane with $10 \mathrm{kDa}$ used for the production of reduning injection, a botanical injection in China. Among major pyrogens that could only be qualitatively analyzed by rabbit fever reaction, bacterial endotoxins (BEs) can be quantitatively detected and can represent the level of pyrogens. Bacterial endotoxin has a natural surfactant characteristic ${ }^{2}$ and can be found in aggregated form in aqueous solutions $\mathrm{s}^{3,4}$. Its monomer, an amphiphile, has a large hydrophilic polysaccharide chain and a hydrophobic fatty acid tail, which accounts for the varying character of the bacterial endotoxin micelle molecular weight $(10 \mathrm{kDa} \text { to } 1000 \mathrm{kDa})^{5}$.
Generally, the limit for pyrogen is $5.0 \mathrm{EU} /(\mathrm{kg} \cdot \mathrm{h})$ body weight per injection ${ }^{5}$. Therefore, no more than $5 \mathrm{EU}$ of pyrogen per $\mathrm{kg}$ of body weight per $\mathrm{h}$ can be parenterally introduced into the human body. Considering the bacterial endotoxin limitation of injections, the ultrafiltration membrane molecular weight cut off (MWCO) of $10 \mathrm{kDa}$ is always used to remove pyrogens. However, chemical composition retention and pyrogen rejection are seemingly difficult to balance during injection administration. Ultrafiltration could be useful in removing endotoxin micelles for micromolecules ${ }^{6}$, but not for macromolecules ${ }^{7}$. Furthermore, many studies have used several modification methods to improve the transfer property ${ }^{8,9}$, separation characteristics ${ }^{10,11}$, antifouling property ${ }^{12,13}$, and other characteristics of the membranes. Ultrafiltration technology may be a universally applicable process for bacterial endotoxin removal.

Salvia injection is widely used for the treatment of cardiovascular diseases and chronic renal failure, accounting for the usage of one million persons in China. We previously reported that commercial ultrafiltration membrane materials, such as cellulose and polysulfone, with $10 \mathrm{kDa}$ could effectively remove bacterial endotoxin. However, such removal is accompanied 
by a high loss of salvianolic acid B. Salvianolic acid B could be satisfactorily retained but the bacterial endotoxin removal rate may decline when the membrane molecular weight cut off is increased.

This study aimed to demonstrate the state change of bacterial endotoxin micelles with different materials and identifies a way to retain the active components while effectively removing bacterial endotoxin by ultrafiltration membranes with suitable molecular weight cut off. Different molecular weight cut offs and materials of ultrafiltration membrane were selected to filter the bacterial endotoxin solution and the salvia injection. A laser particle size analyzer was used to analyze the bacterial endotoxin micelle state. The rejection of bacterial endotoxin and salvianolic acid B was calculated and the relationship between bacterial endotoxin rejection and micelle size was analyzed to elucidate the progress of removal of bacterial endotoxin and to improve the application of ultrafiltration technology on injections.

\section{EXPERIMENTAL}

Salvia injections were bought from Shanghai Worldbest Anhui Jinhui Pharmaceutical Co., Ltd. (Lot No. 10020505). Salvianolic acid B was procured from the National Institute for the Control of Pharmaceutical and Biological Products in China (Lot No. 110704). A high-performance liquid chromatograph manufactured by Agilent Technologies Co., Ltd. (Mode: 1100 ) with $4.6 \mathrm{~mm} \times 25 \mathrm{~mm}$ octadecylsilyl-2 silica gel column equipped with a variable wavelength detector (286 nm wavelength) and an Agilent chromatography workstation were used to determinate the concentration of salvianolic acid $\mathrm{B}$. The detection conditions were as follows: solvent A, $0.1 \%$ formic acid-water; solvent $\mathrm{B}$, acetonitrile; injection volume, $10 \mu \mathrm{L}$; flow rate, $1 \mathrm{~mL} / \mathrm{min}$.

Bacterial endotoxin standard substances were bought from the National Institute for the Control of Pharmaceutical and Biological Products in China (Lot No. 150601-201070). Limulus amebocyte lysate (LAL) was manufactured by Zhanjiang Bokang Ocean Creature Co., Ltd. in China (Lot No. 1003090, $\lambda=0.03 \mathrm{EU} / \mathrm{mL})$. The bacterial endotoxin detector was purchased from Tianda Tianfa Technology Co., Ltd. in China (Mode: BET-16M) and used to detect bacterial endotoxin concentration. The size distribution of bacterial endotoxin was measured by Malvern ZEW3600 Zetasizer Nano System purchased from Malvern Instruments.

Two spiral wound membranes manufactured by Millipore Co. in USA (Cat. No. CDUF006TQ) were used as the filter media. Another two hollow fiber membranes were bought from Wuxi Ultrafiltration Equipment Factory in China. The property details are listed in Table-1.

Adsorption rate experiment: All the ultrafiltration membranes were stored in $25 \mathrm{mmol} / \mathrm{L}$ sodium hydroxide aqueous solutions to protect the membranes from the contaminant of bacterial endotoxin. They were rinsed by purified water until the $\mathrm{pH}$ value was neutral before ultrafiltration use.

The effects of membrane adsorption on bacterial endotoxin were studied. Bacterial endotoxin was dissolved in 1.0 L water with 295.1 and $29.5 \mathrm{EU} / \mathrm{mL}$ to analyze the saturated adsorption of Millipore membranes and Wuxi membranes, respectively. During the experiment, the pipeline of feed solution, filtrate, and rejected solution were placed in the same tube. The filtration operational pressure was controlled under $0.3 \mathrm{~kg} / \mathrm{cm}^{2}$ and the temperature was set to 15 to $18{ }^{\circ} \mathrm{C}$ to maintain the same experiment condition. The filtrate flux was then measured to calculate the circulation volumes. The adsorption was calculated using eqn. 1 . Subsequently, several diagrams were designed using the adsorption as the ordinate and circulation volume similar to the abscissa to find the saturated adsorption. The bacterial endotoxin concentration in the stock solution and the circulation solution were determined by BET-16M.

$$
\text { Adsorption }=\left(\mathrm{C}_{\mathrm{f}}-\mathrm{C}_{\mathrm{s}}\right) \times \mathrm{V}
$$

where $\mathrm{V}$ is the solution volume and $\mathrm{C}_{\mathrm{f}}$ and $\mathrm{C}_{\mathrm{s}}$ are the solute concentrations in the stock solution and circulation solution, respectively.

Bacterial endotoxin solution filtration: The rejection characteristics of bacterial endotoxin were evaluated to analyze the performance of the membranes, excluding the effects of saturated adsorption. The bacterial endotoxin solution filtrated by Millipore membranes and Wuxi membranes and the bacterial endotoxin concentration in the filtrate were determined after the adsorption of membranes had saturated. The rejection was calculated by eqn. 2 .

$$
\text { Solute rejection }(\mathrm{R}, \%)=\left(1-\frac{\mathrm{C}_{\mathrm{p}}}{\mathrm{C}_{\mathrm{f}}}\right) \times 100 \%
$$

where $C_{f}$ and $C_{p}$ are the concentrations of solute in the stock solution and filtrate, respectively.

Ultrafiltration of salvia injection: Salvianolic acid B was selected as the representative component for detection by high-performance liquid chromatography. The concentration of salvianolic acid B was $5.5 \mathrm{mg} / \mathrm{mL}$. Up to $1 \mathrm{~L}$ of stock solution of salvia injection was filtrated by Millipore membranes and

TABLE-1

ULTRAFILTRATION MEMBRANE PROPERTIES

\begin{tabular}{lll|ll}
\hline \multicolumn{1}{c|}{ Properties } & \multicolumn{2}{c}{ Millipore membrane $^{\mathrm{a}}$} & \multicolumn{2}{c}{ Composite material membrane $^{\mathrm{b}}$} \\
\hline MWCO $(\mathrm{kDa})$ & 10 & 50 & 10 & 50 \\
Size $\left(\mathrm{m}^{2}\right)$ & 0.6 & 0.6 & 0.6 & 0.6 \\
Filter material & PES & PES & PES and PVDF & PES and PVDF \\
Wettability & Hydrophilic & Hydrophilic & Hydrophobic & 45.5 \\
Water flux $(1 \mathrm{mh} / \mathrm{psi})$ & 27 & 47.5 & 23.4 & NUF-50 \\
Membrane code & PBGC & PBQK & NUF-10 & $1-12$ \\
pH range & $1-14$ & $1-14$ & $1-12$ & 50 \\
Max operating temperature $\left({ }^{\circ} \mathrm{C}\right)$ & 80 & 80 & 50 & 5
\end{tabular}

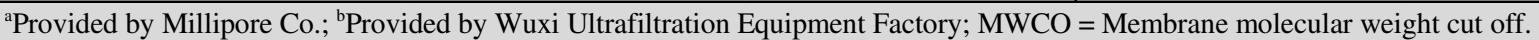


Wuxi membranes. The rejections of the component were calculated using eqn. 2 . The saturated adsorption of salvianolic acid B was investigated using the same approach as the bacterial endotoxin adsorption rate experiments.

Measurements of bacterial endotoxin concentration: Bacterial endotoxin test was conducted by turbidity method. Briefly, a standard substance $(140 \mathrm{EU} / 1 \mathrm{~mL})$ was diluted to 2.0, $0.5,0.125$, and $0.03125 \mathrm{EU} / \mathrm{mL}$. A $100 \mu \mathrm{L}$ portion of each dilution was mixed with the same volume of limulus amebocyte lysate according to the manufacturer's instructions. The reaction mixtures were incubated at $37^{\circ} \mathrm{C}$ and the optical density (OD) was simultaneously monitored. The time required to reach a designated turbidity (OD: 0.02) of the reaction mixtures was measured by BET-16M.

Analyses of the serial samples were performed using least square method. The relationship between bacterial endotoxin concentration and reaction time was as follows:

$$
\log \mathrm{T}=2.9974-0.3241 \log \mathrm{C}
$$

where $\mathrm{T}$ is the reaction time (s) and $\mathrm{C}$ is the bacterial endotoxin concentration $(\mathrm{EU} / \mathrm{mL})$. The related coefficient $\mathrm{r}=$ -0.9910 . The bacterial endotoxin concentration of the stock solution and filtrate was calculated using eqn. 3 .

Measurements of bacterial endotoxin micelle size: The size of bacterial endotoxin micelle in the stock solution was determined using a Malvern laser particle analyzer with the theory of dynamic light scattering (DLS) measured by the Brownian motion and then related to the size distribution. The Brownian motion was performed as random movement of particles caused by the bombardment of the solvent molecules that surround them, and affected by temperature fluctuation and dispersant, among others. Accordingly, $25^{\circ} \mathrm{C}$ was selected as detection temperature and water as dispersant. The wavelength of the laser source was $633 \mathrm{~nm}$ and the water refractive index was 1.330 .

\section{RESULTS AND DISCUSSION}

Adsorption rate of bacterial endotoxin: The dynamic turbidity method was performed using limulus amebocyte lysate to quantify the bacterial endotoxin concentration ${ }^{14,15}$. The saturated adsorption of different membrane materials was investigated for comparison. The results are shown in Fig. 1a and $1 \mathrm{~b}$. The adsorption of all the membranes first increased and then remained stable when the circulation volume was increased. The saturation absorptive capacity of one membrane was different in the bacterial endotoxin solution with 295.1 and $29.5 \mathrm{EU} / \mathrm{mL}$. These results indicate that bacterial endotoxin was adsorbed onto the membranes by kinetic adsorption. The circulation equilibrium volume was $c a .3 \mathrm{~L}$. Therefore, the filtrate circulation volume of $4 \mathrm{~L}$ was chosen for subsequent filtration experiments, and the adsorption constant was affected by the bacterial endotoxin concentration and the membrane material.

Ultrafiltration experiment of the bacterial endotoxin solution: To simulate bacterial endotoxin sudden pollution during preparation of intravenous injections, we chose the concentration of $295.1 \mathrm{EU} / \mathrm{mL}$ to analyze bacterial endotoxin rejection. As shown in Fig. 2 and Table-2, little or no bacterial endotoxin was found in the filtrate of M-10 kDa, C-10 kDa,
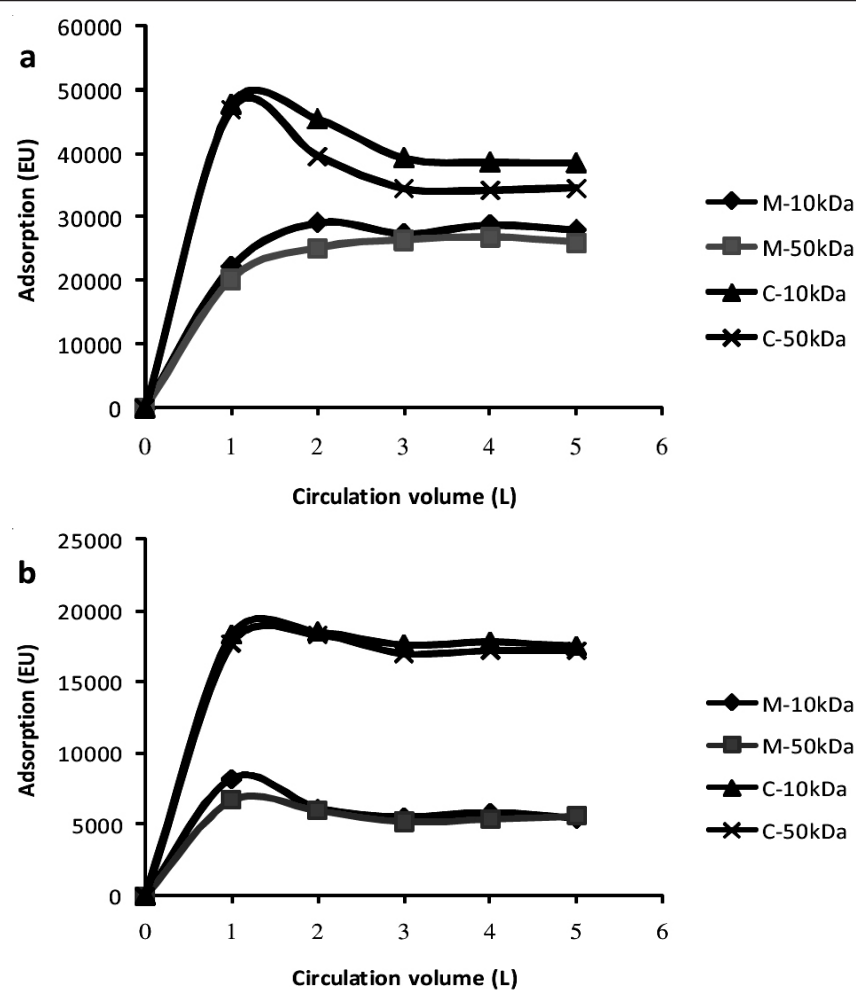

Fig. 1. Bacterial endotoxin adsorption curves with different membranes and concentrations, (a) $295.1 \mathrm{EU} / \mathrm{mL}$; (b) $29.5 \mathrm{EU} / \mathrm{mL}$. M-10 kDa means $10 \mathrm{kDa}$ Millipore membrane; M-50 kDa means $50 \mathrm{kDa}$ Millipore membrane; C-10 kDa means $10 \mathrm{kDa}$ composite material membrane; C-50 kDa means $50 \mathrm{kDa}$ composite material membrane

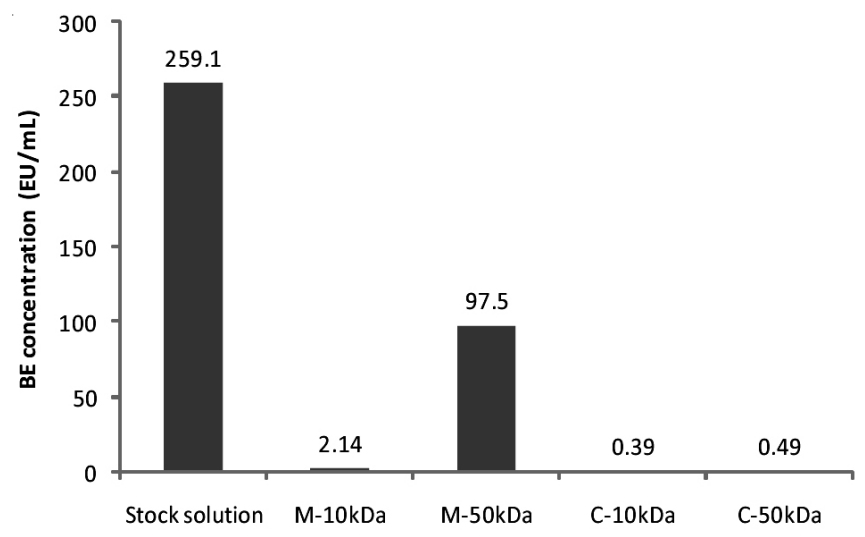

Fig. 2. Bacterial endotoxin concentration in stock solution and filtrate of different membranes.

\begin{tabular}{|c|c|c|c|c|}
\hline \multicolumn{5}{|c|}{$\begin{array}{c}\text { TABLE-2 } \\
\text { BACTERIAL ENDOTOXINS REJECTION OF THE } \\
\text { MILLIPORE AND WUXI MEMBRANES }\end{array}$} \\
\hline & $\mathrm{M}-10 \mathrm{kDa}$ & M-50 kDa & $\mathrm{C}-10 \mathrm{kDa}$ & $\mathrm{C}-50 \mathrm{kDa}$ \\
\hline Rejection (\%) & 93.17 & 62.37 & 99.85 & 99.81 \\
\hline
\end{tabular}

and C-50 kDa. However, the bacterial endotoxin concentration of M-50 kDa was higher than that of C-50kDa, and the above two membranes had the same molecular weight cut off. The composite materials had better bacterial endotoxin rejection than the single material with $50 \mathrm{kDa}$ membrane. The results showed that the bacterial endotoxin micelles could stably exist in salvia injection, but the hydrophilic micelle interface was influenced by different membrane materials. The affinity between the bacterial endotoxin micelles and the membrane 
material also gradually weakened when the membrane material changed from hydrophilic to hydrophobic. Therefore, the micelles were protected and rejected when in contact with the composite membrane materials.

The bacterial endotoxin safety limit of salvia injection is $0.6 \mathrm{EU} / \mathrm{mL}$. However, the hydrophilic ultrafiltration membrane could not ensure the safety of salvia injection with $10 \mathrm{kDa}$. Therefore, most injection manufacturers use $6 \mathrm{kDa}$ ultrafiltration membranes in the production process to control the bacterial endotoxin content to less than the limit, resulting in the loss of salvianolic acid B by greater than $80 \%$. In this study, the composite membrane with $50 \mathrm{kDa}$ could meet the safety limit of bacterial endotoxin with a minimal loss of salvianolic acid B (Figs. 2 and 3).

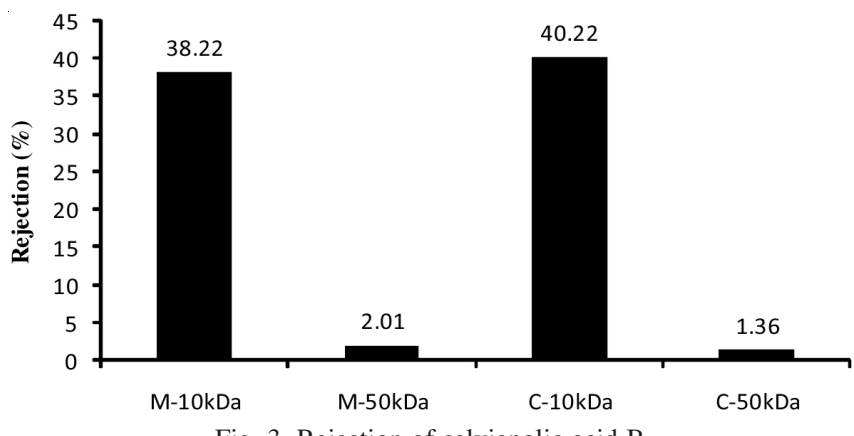

Ultrafiltration experiment of salvia injection: Salvia injection is important in Chinese medicine injection. As shown in Fig. 4, the salvianolic acid B saturated adsorptions of the four membranes were lower than $5 \mathrm{mg}$ when the kinetic adsorption between the salvianolic acid $\mathrm{B}$ and the membranes was balanced. However, the adsorption was negligible compared with the amount of salvianolic acid B in salvia injection. The filtrate circulation volume of $4 \mathrm{~L}$ was chosen for rejection experiments of salvianolic acid $\mathrm{B}$.

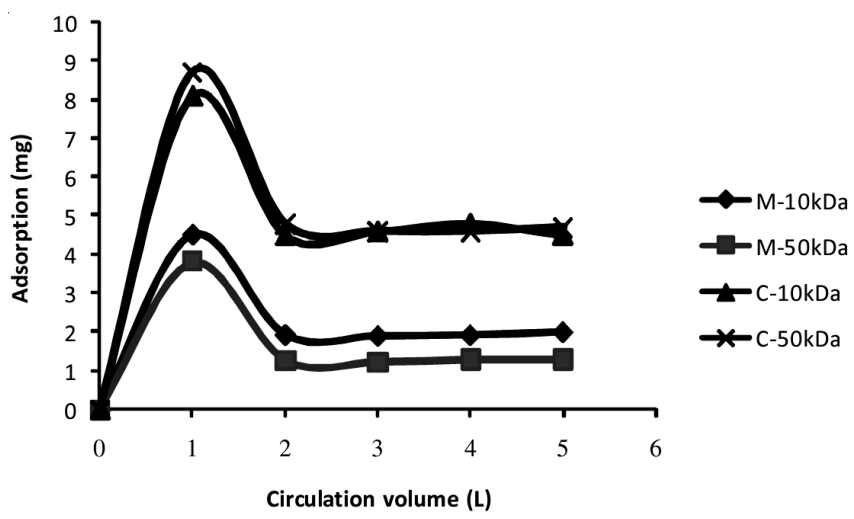

Fig. 4. Salvianolic acid B adsorption curves with different membranes

As shown in Fig. 3, the ultrafiltration rejection of salvianolic acid B with $10 \mathrm{kDa}$ was much higher than that with $50 \mathrm{kDa}$. The rejections of the two components were lower than $5 \%$ and the difference between the Millipore and Wuxi membranes was negligible when the ultrafiltration membrane molecular weight cut off was $50 \mathrm{kDa}$. Considering that the molecular diameter of salvianolic acid B was smaller than the pore size of $50 \mathrm{kDa}$, the molecules that passed through the membrane were less than the membrane aperture and had some big gaps, which have critical values greater than the molecular diameter by over 1.5 times $^{16}$.

Analyses of bacterial endotoxin micelle size and ultrafiltration process: The distribution curves of the bacterial endotoxin micelle size were obtained through the graphic representation of the particle diameter according to their frequency. The bacterial endotoxin monomer was an amphiphile with a large hydrophilic polysaccharide chain and a hydrophobic fatty acid tail, and its monomer could be found in aggregated form (Fig. 5a).
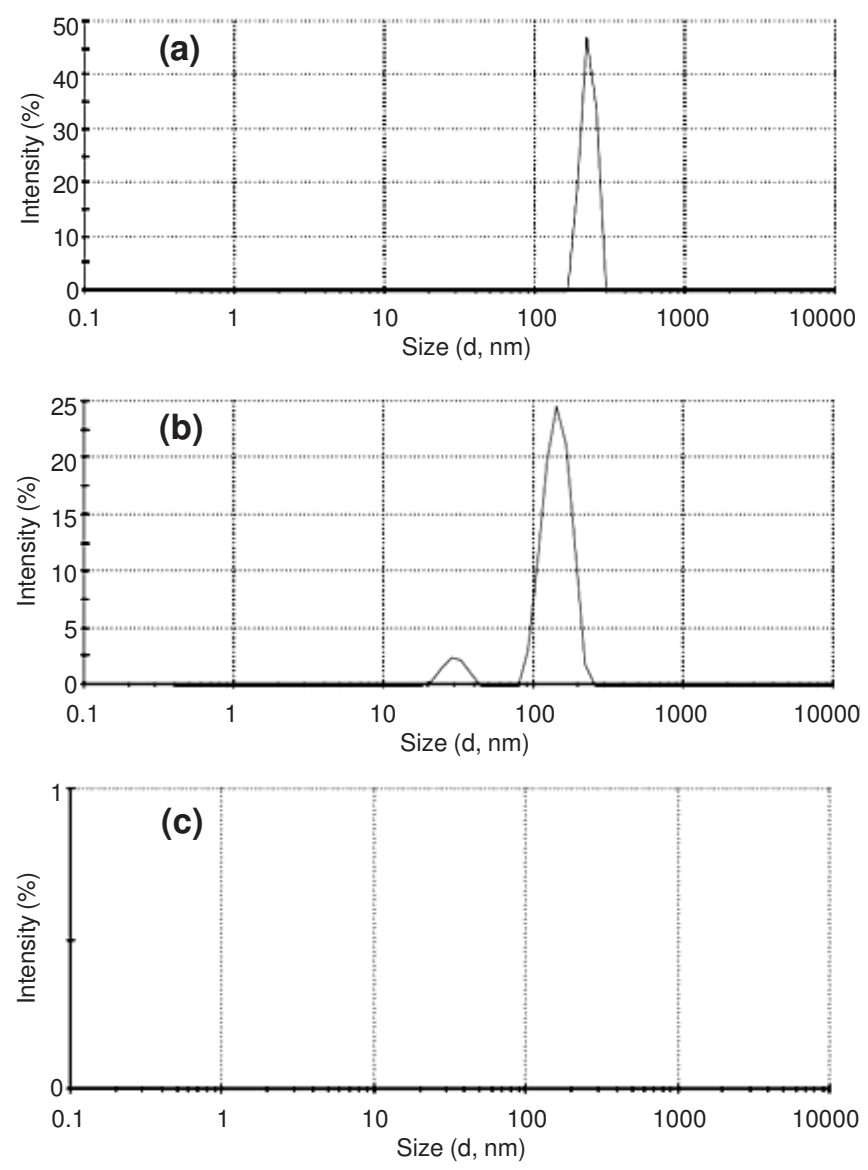

Fig. 5. Particle size distribution of bacterial endotoxin: (a) stock solution, (b) M-50 kDa filtrate, and (c) C-50 kDa filtrate

The bacterial endotoxin micelle size in the stock solution was $468.3 \mathrm{~nm}$ and that of the M-50 kDa filtrate was $214.8 \mathrm{~nm}$. The diameter of most bacterial endotoxin micelles was bigger than the membrane pore apertures of 10 and $50 \mathrm{kDa}$, which suggested that the higher molecular bacterial endotoxin micelles could not be filtered through 10 and $50 \mathrm{kDa}$ of Millipore and Wuxi membranes according to the filtration principle of molecular sieving. However, parts of the micelles passed through the $50 \mathrm{kDa}$ Millipore membrane and were almost entirely rejected by the $50 \mathrm{kDa}$ Wuxi membrane in this experiment.

In contrast to the filtration model of molecule sieving, the results indicated that the affinity between hydrophilic polysaccharide chains and membrane materials was greater than the aggregate force of the bacterial endotoxin micelle during removal of pyrogens by polyethersulfone membranes. 
The bacterial endotoxin micelle was dispersed and could pass through the polyethersulfone membrane when its molecular size was smaller than the radius of the membrane pores and can aggregate again in the filtrate (Fig. 6a).

As shown in Fig. 5c, the particle size distribution of the bacterial endotoxin micelle was blank because its concentration was too low for detection. Fig. $5 \mathrm{~b}$ and $5 \mathrm{c}$ show significant difference. The increase in rejection of the bacterial endotoxin micelle with the Wuxi membrane was typically attributed to interaction between the bacterial endotoxin and the membrane. The affinity between the hydrophilic polysaccharide chain and the membrane material was weaker than the aggregate force of the bacterial endotoxin micelle, and bacterial endotoxin was rejected with aggregate state (Fig. 6b). a
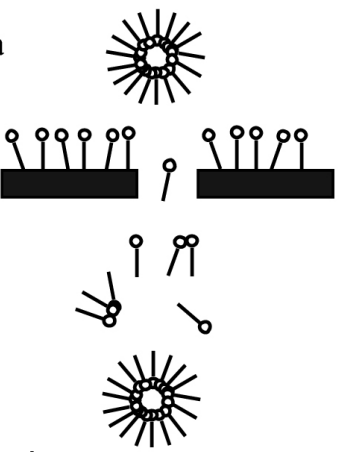

: Bacterial endotoxin micelle; :

Polyethersulfone membrane;

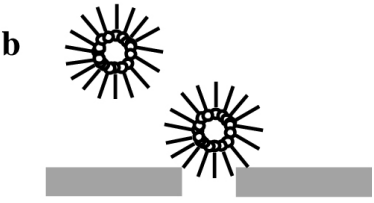

Monomolecular bacterial endotoxin;

Fig. 6. The bacterial endotoxin micelle state during filtration with different membranes: (a) polyethersulfone membrane and (b) composite material membrane.

Molecular sieving was not entirely related to the monomolecular weight of composition permeation through the membranes, but to the molecular weight of composition existence formed (monomolecular, low polymolecular and high polymolecular) in the solution.

\section{Conclusion}

Ultrafiltration is an effective method for removing bacterial endotoxin when retaining the target components with large aperture. The results provide useful information to elucidate the contradictions between chemical composition retention and hazardous material rejection. This study provides a foundation for the study of membrane materials and the improvement of ultrafiltration application for injections.

\section{Abbreviations}

BE: bacterial endotoxin; UF: ultrafiltration; PES: polyethersulfone; PVDF: polyvinylidene fluoride; MWCO: molecular weight cut off; $\mathrm{C}_{\mathrm{f}}$ : solute concentrations in the stock solution; $\mathrm{C}_{\mathrm{p}}$ : solute concentrations in the filtrate; $\mathrm{T}$ : reaction time; $\mathrm{C}$ : BE concentration; $r$ : the related coefficient of curvilinear equation; C-10kDa: $10 \mathrm{kDa}$ composite materials membrane; C-50kDa: 50kDa composite materials membrane; M-10kDa: 10kDa Millipore membrane; M-50kDa: 50kDa Millipore membrane; DLS: dynamic light scattering; OD: optical density.

\section{ACKNOWLEDGEMENTS}

The authors thanks to the State Key Laboratory of New-tech for Chinese Medicine Pharmaceutical Process of China (Project No. SKL2010Z0201), National Science and Technology Support Project of China (Project number: 2006BAI06A04-04), National First-Class Key Discipline for Traditional Chinese Medicine of Nanjing University of Chinese Medicine of China (Project number: 2011ZYX3-008) and the Project Funded by the Priority Academic Program Development of Jiangsu Higher Education Institutions (Project number: PAAD2012-32).

\section{REFERENCES}

1. M. Nagaki, R.D. Hughes, J.Y. Lau and R. Williams, Int. J. Artif. Organs, 14, 43 (1991).

2. G. Reiter, D. Falkenhagen, M. Siam, W. Gollneritsch, D. Baurecht and U.P. Fringeli, Langmuir, 18, 5761(2002).

3. E. Hannecart-Pokorni, D. Dekegel and F. Depuydt, Eur. J. Biochem., 38, 6 (1973).

4. P.O. Magalhães, A.M. Lopes, P.G. Mazzola, C. Rangel-Yagui, T.C. Penna and A. Pessoa Jr., J. Pharm. Pharm. Sci., 10, 388 (2007).

5. M.B. Gorbeta and M.V. Sefton, Biomaterials, 26, 6811 (2005).

6. C. Acconci, C. Legallais, M. Vijayalakshmi and S.M.A. Bueno, J. Membr. Sci., 173, 235 (2000).

7. S.G. Liu, R. Tobias, S. McClure, G. Styba, Q.W. Shi and G. Jackowski, Clin. Biochem., 30, 455 (1997).

8. T. Sukkar and M. Skyllas-Kazacos, J. Membr. Sci., 222, 249 (2003).

9. Q. Yang, Z.K. Xu, Z.W. Dai, J.L. Wang and M. Ulbricht, Chem. Mater, 17, 3050 (2005).

10. K. Kuraoka, Y. Chujo and T. Yazawa, J. Membr. Sci., 182, 139 (2001).

11. P.P. Wang, J. Ma, Z.H. Wang, F.M. Shi and Q.L. Liu, Langmuir, 28, 4776 (2012).

12. J. Pieracci, J.V. Crivello and G. Belfort, J. Membr. Sci., 156, 223 (1999).

13. Y.C. Chiag, Y. Chang, W.Y. Chen and R.C. Ruaan, Langmuir, 28, 1399 (2012).

14. C. McLeod and W. Katz, J. Biol. Stand., 9, 299 (1981).

15. K.G. Ong, J.M. Leland, K.F. Zeng, G. Barrett, M. Zourob and C.A. Grimes, Biosens. Bioelectron., 21, 2270 (2006).

16. J.-S. Park, N. Her, J. Oh and Y.M. Yoon, Chemosphere, 77, 228 (2009). 